\title{
Nota crítica sobre Francisco Galán Vélez, Una metafísica para tiempos posmetafísicos. La propuesta de Bernard Lonergan de una Metametodología, México: Universidad Iberoamericana, 2015, 488 p.
}

\author{
A Critical Note about Francisco Galán Vélez, Una Metafísica \\ para tiempos posmetafísicos. La propuesta de Bernard \\ Lonergan de una Metametodología, Mexico: Universidad \\ Iberoamericana, 2015, $488 \mathrm{p}$.
}

Paniel Osberto Reyes Cárdenas Universidad Popular Autónoma del Estado de Puebla, Puebla panielosberto.reyes@upaep.mx

\section{Resumen}

Esta nota crítica estudia la obra reciente del Prof. Francisco Galán en su proyecto de presentar una metafísica para tiempos pos-metafísicos, es decir, el retomar la tarea de reconstruir la estructura inteligible de la realidad a partir del reconocimiento de la estructura del conocimiento humano en sus distintos patrones de experiencia y articulado por el deseo desasido de conocer. El Profesor Galán encuentra inspiración en el trabajo del Jesuita canadiense Bernard Lonergan y presenta su proyecto como un comentario extendido y una propuesta para considerar seriamente las propuestas del mismo.

Palabras clave: Metafísica, metodología filosófica, Lonergan, meta-metafísica

\section{Abstract}

This is a critical note of the recent book of Prof. Francisco Galán and his project of introducing a Meaphysics for post-metaphysical times, i.e., his endeavour to undertake a reconstruction of the intelligible structure of reality from the discovering of the structure of human knowledge in the different pattern of experiences and articulated by a pure desire of knowing. Professor Galán fins inspiration in the works of the Canadian Jesuit philosopher Bernard Lonergan and introduces his own project as an extended comment and a proposal to consider seriously Lonergan's insights.

Keywords: Metaphysics, Philosophical Methodology, Lonergan, Meta-metaphysics 
El libro de Francisco Galán es sin duda, una línea divisora entre la literatura previa y la literatura por venir en estudios sobre Lonergan, y también en discusiones sobre el futuro de la metafísica; Galán se convertirá en una referencia obligada para estudiar a Lonergan en la vida académica de Latinoamérica.

Como afirma Phil McShane en el prólogo a Una metafísica para tiempos posmetafísicos..., este libro refleja la "aventura filosófica" de nuestro autor, quien se sumerge en una sincera y desasida tarea de buscar el conocimiento consistente con la filosofía de Lonergan, y que refleja el compromiso no sólo de interpretación, sino de apropiación de la filosofía. En efecto, Francisco Galán comienza su libro con una diagnosis del pobre estado de abandono del pensamiento metafísico serio, no porque haya falta de preguntas relevantes asociadas a la metafísica, sino porque la investigación metafísica misma parece seriamente desacreditada en distintas maneras. De este modo, y consecuentemente, Galán nos presenta cuatro importantes retos presentes en la historia que acrisoló el estado contemporáneo de la filosofía, y que requieren una respuesta si es que se desea hacer metafísica seriamente. Kant presenta el primero de estos retos, ${ }_{1}^{1}$ pues fue el primero en ofrecer una crítica seria a la metafísica racionalista en la que ataca el realismo ingenuo y propone el idealismo trascendental. Por su parte, la crítica de Heidegger de la ontología como una reducción del ser y el consiguiente rechazo de la metafísica como un proyecto sin esperanzas es uno de los retos más punzantes. ${ }^{2}$ Más cuestionamientos vienen aún del ataque nietzscheano a la idea de la objetividad reflejada en nuestra concepción de los hechos: "no hay hechos, sólo interpretaciones", ${ }^{3}$ reza el slogan que duda incluso de la posibilidad de la objetividad de los hechos como la asume el realismo ingenuo. Este tipo de reto ataca la base de la metafísica como una descripción de la estructura simétrica entre conocimiento y realidad. Finalmente, la última objeción a la metafísica que el Profesor Galán considera está vinculada a los pensamientos del llamado "Segundo" Wittgenstein, quien afirma que no hay un punto de vista privilegiado en la que la realidad sea descrita directamente, pues hay múltiples formas de vida que constituyen distintos juegos del lenguaje.

El libro se sitúa en el deseo de revivir la metafísica y construir una comunidad seria de investigación en busca de la autoapropiación del conocimiento, que, en palabras de Bernard Lonergan (1904-84), podemos identificar como "Cosmópolis". Francisco Galán explora seriamente las contribuciones de este gran filósofo y jesuita canadiense.

1 Galán Vélez, Francisco, Una Metafísica para tiempos posmetafísicos. La propuesta de Bernard Lonergan de una Metametodología, Mexico: Universidad Iberoamericana, 2015, p. 44.

2 Galán Vélez, Francisco, Una Metafísica..., p. 45.

3 Galán Vélez, Francisco, Una Metafísica..., p. 47. 
Nota crítica sobre Francisco Galán Vélez, Una metafísica para tiempos

Hay dos tesis que podemos identificar en el estudio de Francisco Galán, que podemos entender como consideraciones que satisfacen el reto a la investigación metafísica contemporánea:

1. La metafísica es una estructura heurística que alcanza toda la realidad, pero que hemos de apropiarnos a través de una teoría de las operaciones cognitivas que hablan de los seres que corresponden a dicha estructura.

2. Hay, en efecto, una estructura isomórfica entre los objetos de nuestras actividades cognitivas y la estructura de la realidad conocida, dicho isomorfismo es capturado en el concepto de ser, concepto importantísimo dada su naturaleza unificadora.

El profesor Galán muestra que la definición de la metafísica ha de partir del ser, y en este sentido, la filosofía de Bernard Lonergan es una digna continuación de las ideas de Tomás de Aquino, Duns Escoto, Cayetano y otros. Lonergan, sin embargo, se separó de todos ellos, como lo hizo Kant, en el hecho de que trata de introducir el descubrimiento de una teoría de las operaciones cognoscitivas que permiten que el concepto de objetividad sea plausible. Para realizar dicha tarea, el profesor introduce la metafísica de Lonergan para encontrar el horizonte común que integra los diferentes materiales que vienen de los distintos patrones de la experiencia, como si se presentara a un horizonte de los distintos horizontes que constituyen la conciencia humana polimórfica con sus distintos patrones. Así, en el Capítulo VI se presenta la metafísica como la base semántica que integra toda la unidad requerida entre las distinciones que fueron introducidas en los capítulos previos. En el Capítulo VII, por su parte, el profesor Galán nos presenta la metafísica como un tipo particular de dialéctica en el que se evalúan las posiciones y se confrontan las contraposiciones ante una noción determinada tanto del ser como de la realidad. Explica que estas perspectivas distintas construyen una hermenéutica metódica que forma una metafísica entendida como metodología, o para estar en sintonía con el lenguaje lonerganiano, una metafísica como método.

Uno de los logros notables del libro de Francisco Galán es la habilidad para reconstruir la propuesta de Lonergan de la metafísica heurística del ser proporcionado, así como una narrativa plausible del propio desarrollo de Lonergan en cuanto pensador metafísico. En este proceso, Galán persigue las conexiones que articulan el pensamiento metafísico que encontramos en los trabajos de Lonergan, que constituyen Verbum (una serie de ensayos sobre Santo Tomás de Aquino), como se explica en el Capítulo I. En los capítulos siguientes, se incluye una detallada lectura del Insight. Y en el Capítulo VIII, la explicación del desarrollo de Lonergan en las relaciones que se encuentran entre Insight y Method in Theology, así como también se completa la imagen de la metafísica a través del concepto de las especialidades funcionales. 
La extensión de este libro es de por sí considerable, por lo cual uno no podría reprender al autor el que muchos temas no estén considerados a profundidad, sino sólo mencionados. Con todo, el profesor Galán se preocupó por elaborar un listado muy completo de notas y un aparato crítico que arroja claridad sobre muchos de los temas que nos permiten mayor profundización. A pesar de este gran trabajo, se suele echar de menos el que la discusión hable de la "filosofía analítica", esto es, la filosofía de inspiración lógica y preocupada por el rigor argumental y los problemas filosóficos después del giro lingüístico, en términos poco muy amplios. En efecto, uno se lleva la impresión de que el profesor suele considerar a estos filósofos de manera general y de que discute sus posiciones sobre metafísica muy sucintamente. Esta ausencia es un tanto sorpresiva, puesto que la llamada "metafísica analítica", así como la llamada "meta-ontología" y "meta-metafísica" de inspiración analítica, parecen comportar no sólo un resurgimiento de la metafísica, sino también un florecimiento profesional de la disciplina. Muy abundante literatura que discute a la meta-metafísica o a la meta-ontología ha inspirado trabajos no sólo desde autores como Quine o Van Inwagen en el siglo XX, sino literatura propiamente dedicada a la legitimidad de la teoría metafísica en autores como D. M. Armstrong, E. J. Lowe, Francesco Berto y Tuomas Tahko, por mencionar algunos. Esta literatura parece de hecho coincidir con la dirección que el enfoque del profesor Galán, inspirado en Lonergan, da a los aspectos metodológicos de la metafísica, en cuanto convergen de maneras muy interesantes e importantes.

En conexión con los temas de esta literatura parece que el libro del profesor Galán deja abierta la cuestión de la relación de la lógica y, particularmente, de la lógica modal con la metafísica. Efectivamente, la metafísica de lo posible y de lo necesario parece ser el prolegómeno contemporáneo a los escritos sobre metafísica; y uno se pregunta si Lonergan, desde su particular aristotelismo (y desde su particular interpretación de los filósofos medievales), es una voz que se ha de oír con respecto a estos planteamientos contemporáneos.

Con respecto a contribuciones insospechadas del libro del profesor Galán, quiero seleccionar el interesante argumento que proporciona luz sobre la discusión entre Lonergan y la tradición pragmatista: el profesor Galán explica, ${ }^{4}$ citando a Lonergan, que la conexión última entre metafísica y epistemología está clarificada por nuestro compromiso intelectual pragmático que hace a nuestro conocimiento no absoluto, sino confiable. Lonergan aparece defendiendo, en la interpretación de Francisco Galán, no un fundacionalismo de la epistemología o de la metafísica, sino un pragmatismo coherente que propone un realismo crítico. Dicho realismo es la mejor opción que expresa nuestros compromisos con el deseo intelectual y el desasido deseo por el conocimiento.

4 Galán Vélez, Francisco, Una Metafísica..., pp. 451-452. 
Creemos que este libro es altamente exitoso en ofrecernos un tratamiento comprehensivo de la metafísica (con más de 450 páginas) hecha con un comprometido acercamiento filosófico, y que definitivamente responde a los retos que ve en los filósofos que han puesto la investigación metafísica en entredicho. El libro muestra, asimismo, a través del debate razonado, que la metafísica no es un negocio anticuado en tiempos en los que los posmodernos derivan consecuencias fatales de autores como Kant, Heidegger, Nietzsche y Wittgenstein, puesto que sus argumentos plantean retos que estimulan el pensamiento metafísico. Galán muestra que una metafísica consistente es no sólo plausible sino deseable; que necesitamos aprender las lecciones de las fallas pasadas sin quedar desilusionados o sesgados en nuestro análisis de la poliforme consciencia humana que puede o no recibir los sesgos del pensamiento. La metafísica, en cuanto ciencia del ser proporcionado, como queda definida después del acercamiento a Lonergan, es una tarea que canaliza la estructura plural de la realidad en el deseo irrestricto por el conocimiento que caracteriza el patrón intelectual de la humanidad. En tanto que haya humanos, habrá necesidad de darle sentido a los seres que encontramos en la realidad, animados a seguir los preceptos trascendentales implícitos en la estructura polimórfica de la consciencia: sé atento, sé inteligente, sé razonable, sé responsable.

Francisco Galán nos ha mostrado un compromiso serio con estos preceptos al lograr en este libro una propuesta de una opción inteligente para renovar el pensamiento metafísico. Esperamos, por tanto, que el libro del profesor Galán siga generando una discusión tanto en los círculos en los que se estudia a Lonergan como en la investigación metafísica en general. 